\title{
Efek Variasi Komposisi dan Waktu Milling terhadap Sifat Fisis dan Kuat Tekan Keramik Clay
}

\author{
Afifah Alif Mahdalena*, Mora \\ Laboratorium Fisika Material, Jurusan Fisika \\ Fakultas Matematika dan Ilmu Pengetahuan Alam Universitas Andalas \\ Kampus UNAND Limau Manis, Padang, 25163 Indonesia \\ *afifahrindila@gmail.com
}

\begin{abstract}
ABSTRAK
Telah dilakukan penelitian mengenai efek variasi komposisi dan waktu milling terhadap sifat fisis dan kuat tekan keramik clay. Clay dimilling menggunakan ball mill dengan variasi waktu 5 dan 10 jam. Sampel dibuat dengan perbandingan massa clay yang tidak dimilling dengan clay yang dimilling adalah 100\%:0\%, 90\%:10\%, 80\%:20\%, 70\%:30\%, 60\%:40\%, 0\%:100\%. Susut bakar keramik clay minimum adalah 17,3\% yang terdapat pada komposisi campuran massa 60\%:40 \% yang dimilling selama 5 jam. Nilai densitas keramik tertinggi terdapat pada komposisi massa 60\%:40\% clay yang dimilling 5 jam yaitu $1,853 \mathrm{gr} / \mathrm{cm}^{3}$. Porositas terendah pada komposisi massa $80 \%: 20 \%$ clay yang dimilling 5 jam yaitu 25,21 $\%$. Kuat tekan tertinggi pada komposisi massa 60\%:40\% yang dimilling 5 jam yaitu 584,03 kg/ $\mathrm{cm}^{2}$. Hasil XRD menunjukan clay mengandung mineral kaolinit, illite, dan kuarsa. Ukuran kristal clay tidak dimilling yaitu 105,381 nm, setelah dimilling 5 jam menjadi 100,058 nm dan setelah milling 10 jam menjadi 94,335 nm. Hasil SEM menunjukan ukuran partikel clay tidak dimilling adalah 12,083 $\mu \mathrm{m}$, setelah dimilling 5 jam menjadi $9,005 \mu \mathrm{m}$ dan setelah dimilling 10 jam menjadi $18,9 \mu \mathrm{m}$.

Kata kunci : keramik clay, clay, milling, susut bakar
\end{abstract}

\section{ABSTRACT}

A research on effect of composition variation and milling time on physical and compressive strength of ceramic clay have been done. Clay was milled by using a ball mill with 5 and 10 hours varying time. Sample made with comparision mass of clay not milling with clay milling is 100\%:0\%, 90\%:10\%, 80\%:20\%, 70\%:30\%, 60\%:40\%, 0\%:100\%. Sample with composition of 60\%:40\% have the minimum ceramic percentage burn shrinkage (17.3\%), a highest ceramic density $\left(1.853 \mathrm{gr} / \mathrm{cm}^{3}\right)$, and highest compressive strength $\left(584.03 \mathrm{~kg} / \mathrm{cm}^{2}\right)$ all with time of 5 hours. The lowest porosity at $80 \%: 20 \%$ clay milling time of 5 hours that is $25.21 \%$. XRD results show that clay contains mineral is kaolinite, illite, and quartz. The crystal size of not milling clay is $105.381 \mathrm{~nm}, 100.058 \mathrm{~nm}$ of milling clay in 5 hours and $94.355 \mathrm{~nm}$ of milling clay in 10 hours. SEM results show that the clay particle size of not milling clay is $12.083 \mu \mathrm{m}, 9.005 \mu \mathrm{m}$ of milling clay in 5 hours and $18.9 \mu \mathrm{m}$ of milling clay in 10 hours.

Keywords: burn shrinkage, ceramic clay, clay, milling

\section{PENDAHULUAN}

Indonesia memiliki potensi cadangan tanah liat / clay sangat besar dan tersebar hampir di seluruh daerah, antaranya kab. Tanah Datar prov. Sumatera Barat, terdapat cadangan hipotetik clay sebanyak 1.250.000 ton (Distamben, 2002). Melimpahnya keberadaan clay di kab. Tanah Datar membuat masyarakat berfikir kreatif untuk memanfaatkan clay menjadi suatu produk yang memiliki nilai jual. Clay mempunyai sifat plastis bila basah dan sangat keras bila dibakar pada suhu tinggi (Gonggo, 2001) sehingga clay dapat digunakan sebagai bahan keramik. Daerah jorong Galogandang kec. Rambatan kab. Tanah Datar dikenal sebagai daerah pengrajin keramik clay di Sumatera Barat. Produk keramik yang dihasilkan dari industri keramik daerah Galogandang yaitu berupa batu bata dan gerabah.

Kegiatan industri keramik seperti bata merah, genteng, gerabah dan lain-lain tidak berpengaruh terhadap krisis moneter, bahkan dengan menurunnya nilai rupiah justru memberikan nilai ekspor yang tinggi karena semakin tingginya pasaran keramik seperti gerabah ke manca negara, seperti Australia, Amerika, Jepang, Belanda dan Perancis (Rifai dan Hartono, 2016).

Beberapa peneliti telah melakukan kajian untuk mengetahui maupun meningkatkan kualitas keramik clay dalam rangka menunjang pengembangan usaha kerajinan keramik di Indonesia, misalnya Hajiyanti (2007) melakukan pengujian optimasi suhu pembakaran untuk meningkatkan kualitas genteng keramik berbahan baku clay daerah desa Kemiri, kec. 
Kebakkramat, kab. Karanganyar. Variasi suhu yang digunakan yaitu $500^{\circ} \mathrm{C}$ sampai $1000^{\circ} \mathrm{C}$, diperoleh hasil terbaik dalam proses pembakaran yaitu pada suhu $900^{\circ} \mathrm{C}$, dengan nilai susut bakar $1.15 \%$ dan nilai kerapatan $1.64 \mathrm{gr} / \mathrm{cm}^{3}$. Herdiansah (2006) melakukan penelitian tentang pengaruh pencampuran pasir pada bahan baku clay terhadap kualitas keramik dari industri keramik desa Kemiri, kec. Kebakkramat, kab. Karanganyar. Pada penelitian ini proses pembakaran dilakukan pada suhu $700^{\circ} \mathrm{C}$ dan diperoleh hasil bahwa variasi komposisi massa yang paling baik adalah $80 \%$ clay dan $20 \%$ pasir. Namun pada penelitian ini tidak dilakukan pengujian sifat mekanis berupa kuat tekan pada keramik clay.

Sanjaya (2009) melakukan pengujian pengaruh jumlah penggilingan clay sebagai bahan pembuatan genteng terhadap karakteristik keramik Darmasaba. Pada pengujian ketahanan perembesan air, clay yang dua kali penggilingan tahan terhadap perembesan air dibandingkan dari clay satu penggilingan, nilai susut bakar yang diperoleh pada clay dua kali penggilingan yaitu $1,9 \%$ kecil dibandingkan dengan clay yang satu kali penggilingan yaitu $2,2 \%$. Namun pada penelitian yang telah dilakukan tersebut memiliki beberapa kekurangan diantaranya tidak dilakukan analisa ukuran partikel pada clay yang telah digilling, dan tidak dilakukan pengujian sifat mekanik.

Nasir dkk (2017) melakukan penelitian milling kaolin variasi waktu 0 jam, 6 jam, 12 jam dan 18 jam menggunakan high energy milling, waktu optimum untuk penggilingan yaitu 12 jam, hal ini didasarkan pada distribusi ukuran partikel yang seragam (homogen) dengan hasil ukuran $158 \mathrm{~nm}$ dan $64 \mathrm{~nm}$. Penggilingan merupakan salah satu cara untuk merubah ukuran menjadi kecil, metode penggilingan yang biasa digunakan yaitu stamp mill dan ball mill. Metode paling efektif yaitu metode ball mill, karna waktu penggilingan lebih cepat dan hasil penggilingan lebih halus (Widjanarko,2014).

Berdasarkan keterbatasan penelitian sebelumnya diperlukan penelitian lebih lanjut mengenai clay yang digunakan utuk pembuatan keramik clay. Dalam penelitian ini clay yang digunakan diperoleh dari daerah kel. Galogandang kec. Rambatan kab. Tanah Datar. Pembuatan keramik clay menggunakan pencetak pelet yang dikempa dengan hot packing press dan di uji sifat fisis serta kuat tekan keramik clay.

\section{METODE}

Penelitian dilaksanakan pada bulan Januari sampai Juni 2018. Penelitian ini menggunakan metode eksperimen dengan pengujian porositas, densitas dan susut bakar di Laboratorium Fisika Material Jurusan Fisika Universitas Andalas. Karakterisasi sampel menggunakan XRD dilakukan di Laboratorium Fisika Material Jurusan Fisika Universitas Negeri Padang, karakterisasi menggunakan SEM dilakukan di Jurusan Teknik Mesin Universitas Andalas, sedangkan pengujian kuat tekan dilakukan di Laboratorium Mekanik Politeknik Negeri Padang.

Bahan baku clay diambil di daerah Galogandang Kec. Rambatan tempat produksi kerajinan keramik, dihancurkan kemudian dikeringkan dengan suhu ruangan selama 7 hari. Clay yang sudah kering kemudian digerus menggunakan lumpang dan alu sehingga, di dapatkan partikel-pertikel atau serbuk clay. Serbuk clay yang diperoleh diayak menggunakan ayakan 100 mesh sebanyak 1320 gr. Serbuk clay hasil ayakan disebut ukuran clay tanpa milling atau milling 0 jam.

Serbuk clay yang telah diayak kemudian dibagi menjadi 3 dan dimilling menggunakan alat ball mill selama 5 jam dan 10 jam masing-masing sebanyak 240 gr. Clay tanpa milling dicampurkan dengan clay milling 5 jam dan clay milling 10 jam, masing masing dengan persentase komposisi massa perbandingan 100\%:0\%, 90\%:10\%, 80\%:20\%, 70\%:30\%, 60\%:40\%, 0\%:100\%, dengan total massa 120 gr.

Setiap serbuk clay yang telah dicampur komposisi massa ditambahkan aquades sebanyak $120 \mathrm{ml}$ kemudian diaduk mengunakan mixer selama 10 menit sehingga membentuk pasta. Clay paduan yang telah membentuk pasta dikeringkan menggunakan oven dengan suhu $150^{\circ} \mathrm{C}$ selama 60 menit. Clay paduan yang telah dikeringkan kemudian dicetak pada pencetak berbentuk tabung dengan diameter $2,85 \mathrm{~cm}$ dan tinggi $1,8 \mathrm{~cm}$, dan dikompaksi dengan hot packing press pada suhu $100^{\circ} \mathrm{C}$ dan diberi tekanan $2000 \mathrm{~kg}$ dengan waktu penahan selama 10 
menit. Sampel yang telah terbentuk disintering menggunakan furnance pada suhu $900^{\circ} \mathrm{C}$ dengan waktu penahanan selama 3 jam.

\subsection{Karakterisasi XRD dan SEM}

Karakterisasi menggunakan XRD dilakukan untuk mengetahui ukuran kristal dan kandungan senyawa pada sampel, SEM dilakukan untuk mengetahui ukuran partikel. Karakterisasi dilakukan pada sampel serbuk clay milling 0 jam, clay milling 5 jam, dan clay milling 10 jam serta keramik yang memiliki kuat tekan terendah dan kuat tekan tertinggi.

\section{HASIL DAN DISKUSI}

\subsection{Analisa hasil pengujian susut bakar}

Dari data pengukuran massa masing-masing sampel keramik clay sebelum dan setelah disintering, di dapatkan nilai susut bakar menggunakan Persamaan 1.

$$
\text { Susut Bakar }(\%)=\frac{M k-M b}{M k} \times 100 \%
$$

$M_{b k}$ adalah massa setelah dibakar (gr) dan $M_{k}$ adalah massa sebelum dibakar (gr). Hasil perhitungan susut bakar keramik clay ditunjukan pada Tabel 1.

Tabel 1 Susut bakar keramik clay

\begin{tabular}{|c|c|c|}
\hline Sampel & Komposisi & Susut Bakar (\%) \\
\hline A & $100 \% 0 \mathrm{jam}$ & 18,55 \\
\hline B & $100 \% 5 \mathrm{jam}$ & 17,90 \\
\hline $\mathrm{C}$ & $100 \% 10$ jam & 22,10 \\
\hline $\mathrm{D}$ & $90 \% 0 \mathrm{jam}: 10 \% 5 \mathrm{jam}$ & 17,87 \\
\hline $\mathrm{E}$ & $80 \% 0 \mathrm{jam}: 20 \% 5 \mathrm{jam}$ & 17,82 \\
\hline $\mathrm{F}$ & $70 \% 0$ jam : $30 \% 5$ jam & 17,73 \\
\hline G & $60 \% 0$ jam : $40 \% 5$ jam & 17,30 \\
\hline $\mathrm{H}$ & $90 \% 0$ jam : $10 \% 10$ jam & 19,24 \\
\hline I & $80 \% 0 \mathrm{jam}: 20 \% 10 \mathrm{jam}$ & 18,99 \\
\hline $\mathrm{J}$ & $70 \%$ 0 jam : $30 \% 10$ jam & 18,60 \\
\hline K & $60 \%$ 0 jam : $40 \% 10 \mathrm{jam}$ & 18,40 \\
\hline
\end{tabular}

Hasil pengujian nilai susut bakar pada penelitian ini berkisar antara 17,30\% hingga $22,10 \%$ Hasil yang didapatkan jauh lebih besar dibandingkan dengan nilai susut bakar clay yang diharapkan yaitu 2,5\%. Hal ini karna nilai susut bakar dipengaruhi oleh beberapa faktor yaitu kandungan senyawa clay, homogenitas ukuran butir dari pencampuran clay dan ukuran partikel clay (Suwardono, 2002).

\subsection{Hasil pengujian densitas keramik clay}

Dari data pengukuran volume dan massa masing-masing sampel keramik clay yang telah disintering, didapatkan nilai densitas menggunakan Persamaan 2.

$$
\rho=\frac{M}{V}
$$

$\rho$ adalah densitas bahan $\left(\mathrm{gr} / \mathrm{cm}^{3}\right), M$ adalah massa benda (gr) dan $V$ adalah volume benda $\left(\mathrm{cm}^{3}\right)$. Pada Tabel 2 menunjukan nilai densitas tertinggi diperoleh pada campuran $60 \%$ clay milling 0 jam dengan $40 \%$ clay yang dimilling selama 5 jam dengan nilai densitas sebesar $1,853 \mathrm{gr} / \mathrm{cm}^{3}$, dan densitas keramik clay terendah terdapat pada campuran clay $100 \%$ clay yang dimilling selama 10 jam dengan nilai densitas sebesar $1,712 \mathrm{gr} / \mathrm{cm}^{3}$. Hasil pengujian densitas keramik clay pada penelitian ini memenuhi standar mutu SNI-03-4164-1996 yaitu 1,6 gr/ $/ \mathrm{cm}^{3}-2,5$ $\mathrm{gr} / \mathrm{cm}^{3}$. 
Tabel 2 Densitas keramik clay

\begin{tabular}{|c|c|c|}
\hline Sampel & Komposisi & Densitas $\left(\mathrm{gr} / \mathrm{cm}^{3}\right)$ \\
\hline $\mathrm{A}$ & $100 \% 0 \mathrm{jam}$ & 1,778 \\
\hline B & $100 \% 5 \mathrm{jam}$ & 1,811 \\
\hline $\mathrm{C}$ & $100 \% 10 \mathrm{jam}$ & 1,712 \\
\hline $\mathrm{D}$ & $90 \% 0$ jam : $10 \% 5$ jam & 1,826 \\
\hline $\mathrm{E}$ & $80 \% 0$ jam : $20 \% 5$ jam & 1,845 \\
\hline $\mathrm{F}$ & $70 \% 0$ jam : $30 \% 5$ jam & 1,830 \\
\hline G & $60 \% 0$ jam : $40 \% 5$ jam & 1,853 \\
\hline $\mathrm{H}$ & $90 \% 0$ jam : $10 \% 10$ jam & 1,838 \\
\hline I & $80 \% 0$ jam : $20 \% 10$ jam & 1,842 \\
\hline $\mathrm{J}$ & $70 \% 0$ jam : $30 \% 10$ jam & 1,797 \\
\hline $\mathrm{K}$ & $60 \% 0$ jam : $40 \% 10$ jam & 1,828 \\
\hline
\end{tabular}

\subsection{Hasil pengujian porositas keramik clay}

Pengujian porositas masing-masing sampel keramik clay dilakukan setelah proses sintering, dari data pengukuran massa sampel sebelum dan setelah direndam dalam aquades selama 24 jam diperoleh nilai porositas menggunakan Persamaan 3.

$$
\text { Porositas }(\%)=\frac{M b-M}{V} \times \frac{1}{\rho} \times 100 \%
$$

$M_{b}$ adalah massa basah sampel setelah direndam (gr), $M$ adalah massa sampel kering (gr), $V$ adalah volume sampel $\left(\mathrm{cm}^{3}\right)$ dan $\rho$ adalah massa jenis air yaitu $1 \mathrm{gr} / \mathrm{cm}^{3}$. Hasil perhitungan porositas ditunjukan pada Tabel 3 berikut:

Tabel 3 Porositas keramik clay

\begin{tabular}{lll}
\hline Sampel & Komposisi & Porositas (\%) \\
\hline A & $100 \% 0$ jam & 26,71 \\
B & $100 \% 5$ jam & 25,21 \\
C & $100 \% 10$ jam & 25,56 \\
D & $90 \% 0$ jam : $10 \% 5$ jam & 26,49 \\
E & $80 \% 0$ jam : 20\%5 jam & 26,54 \\
F & $70 \% 0$ jam : 30\% 5 jam & 26,54 \\
G & $60 \% 0$ jam : 40\% 5 jam & 26,57 \\
H & $90 \% 0$ jam : $10 \% 10$ jam & 26,43 \\
I & $80 \% 0$ jam : 20\% 10 jam & 27,16 \\
J & $70 \% 0$ jam : 30\% 10 jam & 28,01 \\
K & $60 \% 0$ jam : 40\% 10 jam & 26,14 \\
\hline
\end{tabular}

Hasil pengujian porositas keramik clay yang didapatkan berkisar 25.21\%-28.01\%. porositas minimum diperoleh pada keramik clay $100 \%$ milling 5 jam dan nilai porositas maksimum diperoleh pada keramik clay pencampuran $70 \%$ milling 0 jam dengan $30 \%$ milling 10 jam yaitu sebesar $28.01 \%$. Hasil pengujian porositas keramik clay daerah kel. Galogandang kec. Rambatan pada penelitian kali ini memenuhi syarat nilai porositas keramik yang ada dipasaran yaitu antara 20\%-30\% (Kiswanto, 2011).

\subsection{Hasil analisis kuat tekan keramik clay}

Pengujian kuat tekan dilakukan menggunakan mesin UTM dengan meletakan sampel uji pada tumpuan. Lalu sampel uji diberi beban secara vertikal, dan diamati sampai retak. Beban maksimum yang menyebabkan sampel uji retak sebagai nilai $P_{r}$. Setelah itu dilakukan perhitungan nilai kuat tekan menggunkan Persamaan 4.

$$
f_{C}=\frac{P_{r}}{A}
$$


$f_{c}$ adalah Compressive Strength $\left(\mathrm{kg} / \mathrm{cm}^{2}\right), P_{r}=$ Gaya tekan $(\mathrm{kg})$ dan $A=$ Luas sampel $\left(\mathrm{cm}^{2}\right)$. Hasil perhitungan kuat tekan ditunjukan pada Gambar 1.

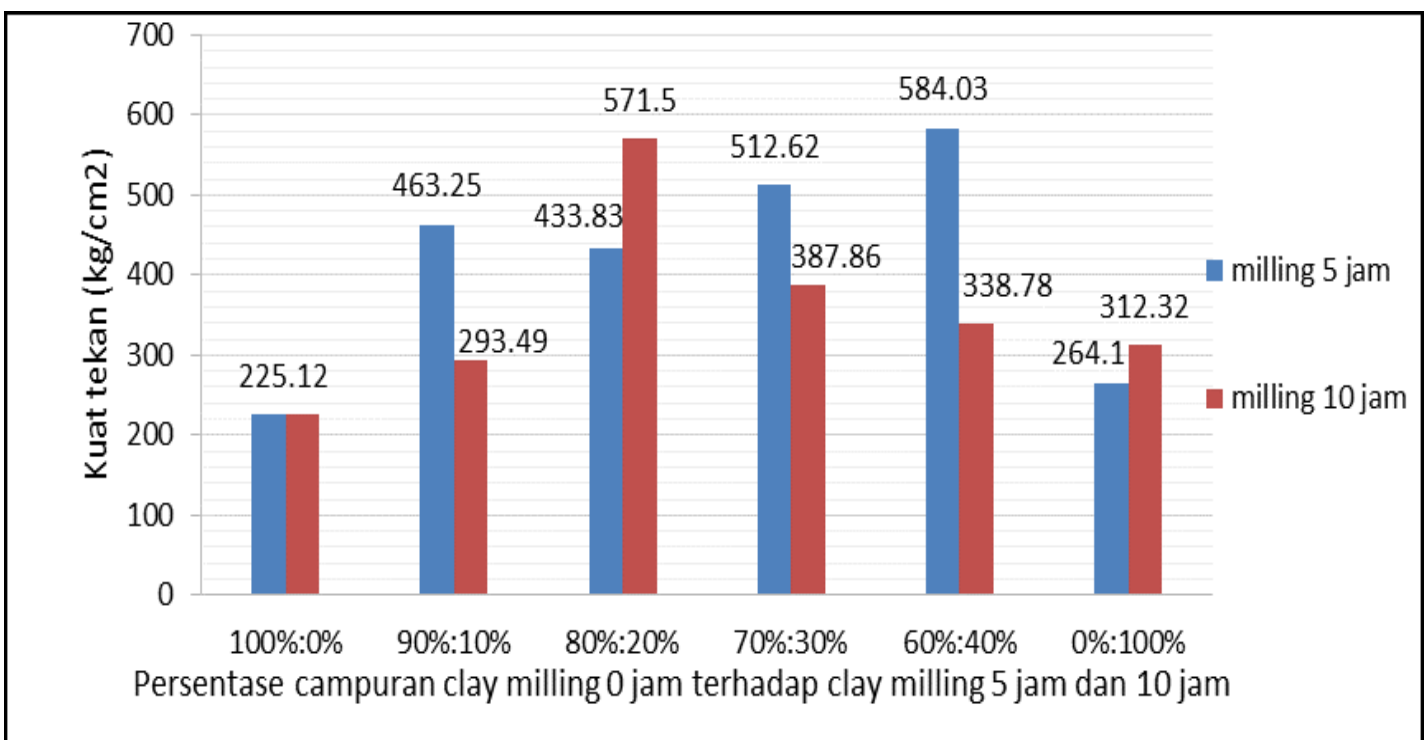

Gambar 1 Grafik Hasil Kuat Tekan Keramik Clay

Gambar 1 menunjukan bahwa pencampuran clay milling variasi waktu mempengaruhi nilai kuat tekan keramik clay. Berdasarkan data kuat tekan keramik yang diperoleh, clay yang berasal dari daerah kel.Galogandang kec. Rambatan kab. Tanah Datar belum bisa digunakan sebagai porselen dengan kuat tekan $4000 \mathrm{~kg} / \mathrm{cm}^{2}-6000 \mathrm{~kg} / \mathrm{cm}^{2}$, tetapi bisa digunakan sebagai bahan produksi gerabah dan batu bata mutu A yang mempunyai nilai kuat tekan yaitu 25 $\mathrm{kg} / \mathrm{cm}^{2}-250 \mathrm{~kg} / \mathrm{cm}^{2}$ (SII-0021-1978).

\subsection{Analisis hasil pengujian $X$-Ray Difraction (XRD)}

Hasil karakterisasi serbuk clay menggunakan XRD dilakukan pada sampel tanpa milling dan hasil analisa XRD dapat dilihat pada Gambar 2.

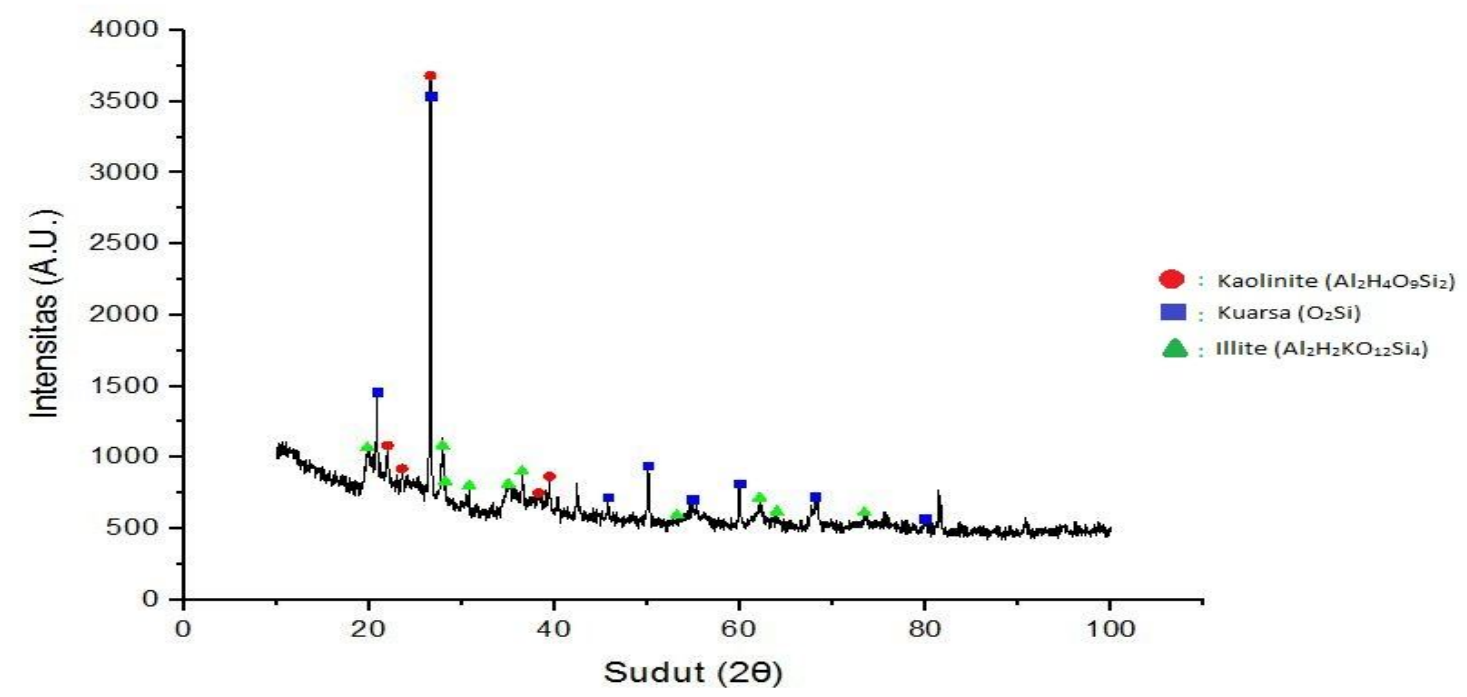

Gambar 2 Grafik XRD serbuk clay

Berdasarkan hasil XRD pada Gambar 2 dapat dilihat bahwa clay dari daerah kel. Galogandang kec. Rambatan kab. Tanah Datar mengandung senyawa kaolinit, illite dan kuarsa. Ukuran kristal pada serbuk clay tanpa milling, clay dimilling 5 jam dan clay dimilling 10 jam 
dihitung menggunakan persamaan scherer dan didapatkan ukuran kristal pada clay tanpa milling yaitu $105.381 \mathrm{~nm}$. Ukuran kristal pada clay dimilling 5 jam yaitu $100.058 \mathrm{~nm}$, sedangkan ukuran kristal clay milling 10 jam yaitu $94.335 \mathrm{~nm}$.

\subsection{Analisis hasil SEM}

Karakterisasi menggunakan SEM dilakukan untuk menentukan ukuran partikel pada serbuk sampel clay tanpa milling (milling 0 jam), clay milling 5 jam dan clay milling 10 jam, hasil SEM clay perbesaran $1000 \mathrm{x}$ dapat dilihat pada Gambar 3.

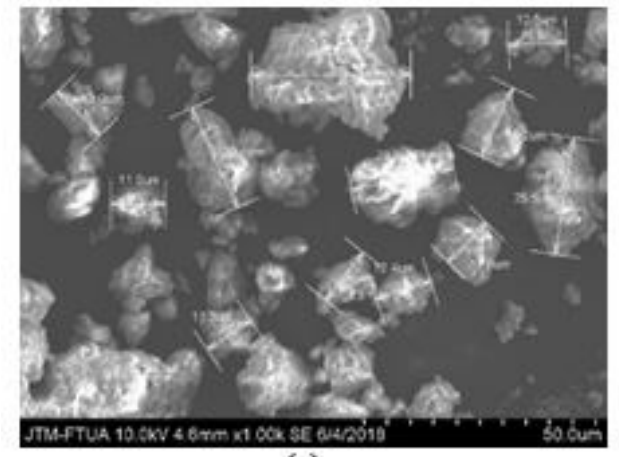

(a)

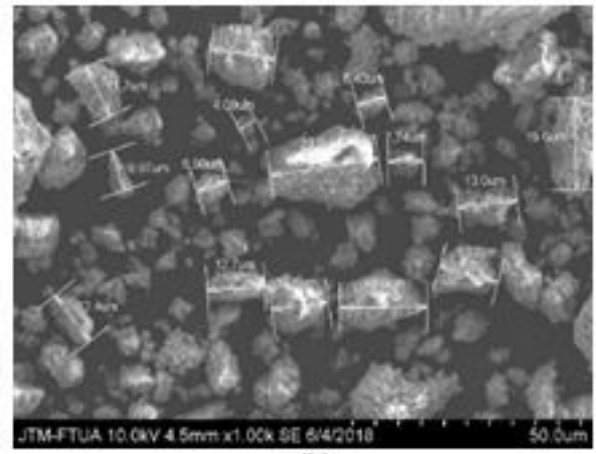

(b)

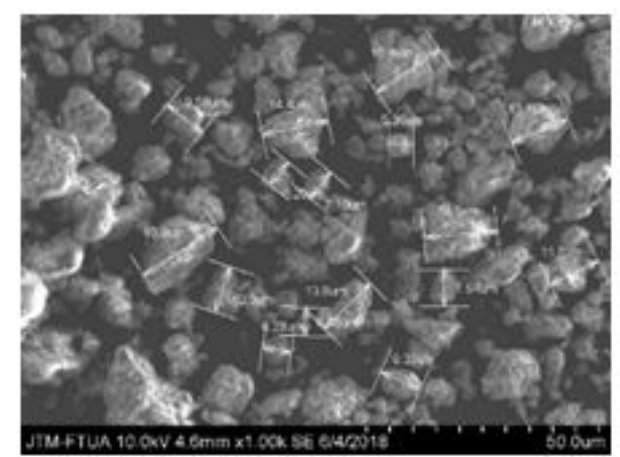

(c)

Gambar 3. Hasil SEM Serbuk Clay dengan Perbesaran 1000 x (a) milling 0 jam, (b) milling 5 jam, (c) milling 10 jam

Berdasarkan Gambar 3 dapat dilihat ukuran partikel masing masing serbuk clay. Ukuran partikel paling besar pada clay milling 0 jam yaitu $34,5 \mu \mathrm{m}$ dengan rata-rata ukuran partikel 12,083 $\mu \mathrm{m}$, ukuran partikel paling besar pada clay milling 5 jam yaitu 23,9 $\mu \mathrm{m}$ dengan rata-rata ukuran partikel 9,005 $\mu \mathrm{m}$ dan ukuran partikel paling besar pada clay milling 10 jam yaitu $18,9 \mu \mathrm{m}$ dengan rata-rata ukuran partikel 8,086 $\mu \mathrm{m}$. Hasil identifikasi serbuk clay milling menggunakan SEM membuktikan bahwa semakin lama waktu milling maka ukuran partikel semakin menggecil tetapi ukuran partikel yang diperoleh tidak homogen, hal ini yang menyebabkan nilai susut bakar keramik clay yang diperoleh besar.

Hasil analisa SEM Gambar 4 menunjukan bahwa jarak antara lempeng-lempeng pada clay tekanan terendah (sampel A) lebih jauh dari pada jarak antara lempeng-lempeng pada clay yang memiliki tekanan tertinggi (sampel G), clay yang telah dibakar mempunyai lempengan tipis dan ukurannya tidak homogen namun lempengan-lempengan tipisnya terlihat sudah mulai menyatu dibandingkan dengan partikel-partikel yang berada pada serbuk clay milling variasi waktu pada Gambar 3. Hal ini disebabkan karena proses penyatuan yang terjadi pada proses sintering, dimana partikel dari mineral feldspar mulai meleleh dan mengisi bagian-bagian pori sehingga keramik terlihat lebih menyatu. 


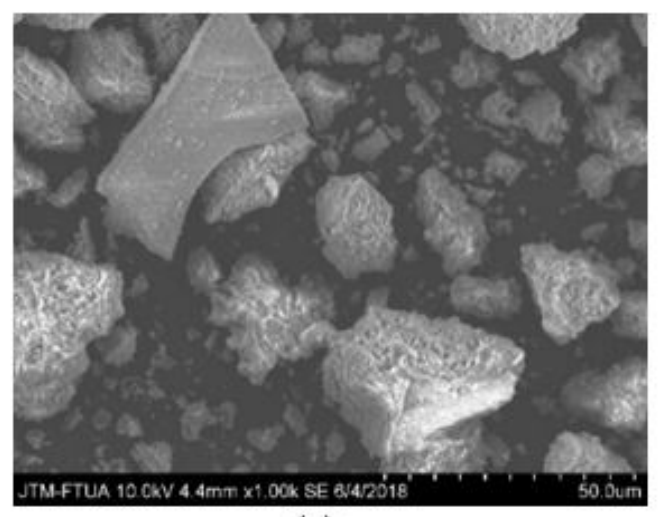

(a)

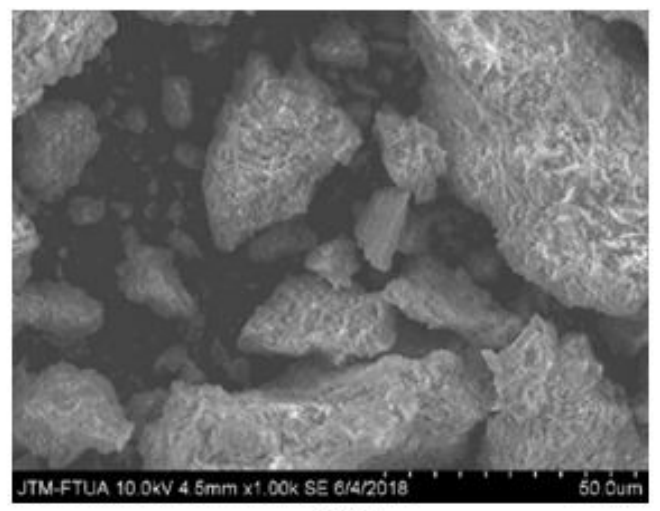

(b)

Gambar 4 Hasil SEM keramik clay (a) sampel A tekanan terendah, (b) sampel G tekanan tertinggi

\section{KESIMPULAN}

Variasi komposisi massa terbaik yaitu pada komposisi campuran $60 \%$ clay tanpa milling dengan $40 \%$ clay milling selama 5 jam yang memiliki nilai kuat tekan tertinggi yaitu $584,03 \mathrm{~kg} / \mathrm{cm}^{2}$, susut bakar terendah yaitu $17,30 \%$, dan densitas tertinggi yaitu $1,853 \mathrm{gr} / \mathrm{cm}^{3}$.

\section{DAFTAR PUSTAKA}

Dinas Pertambangan dan Energi, "Potensi Bahan Galian Se-Sumatera Barat Provinsi Sumbar", (2002).

Gonggo, S. T., "Analisa Mineral Lempung Kelurahan Tatura Palu Sulteng Sebagai Bahan Dasar Keramik", Jurnal Kimia Tadulako, 2, hal 32-34, (2001).

Hajiyanti, I. N., "Optimasi Suhu Pembakaran Bahan Baku Genteng Untuk Meningkatkan Kualitas Genteng Keramik Desa Kemiri Kecamatan Kebakkramat Kabupaten Karanganyar", Skripsi, Fakultas Matematika dan Ilmu Pengetahuan Alam, UNS, Surakarta, 2007.

Herdiansah, Rizal., "Pengaruh Campuran Pasir Terhadap Kualitas Keramik Berbahan Baku Lempung Dari Kecamatan Kebakkramat Kabupaten Karanganyar”, Skripsi, Fakultas Matematika dan Ilmu Pengetahuan Alam, UNS, Surakarta, 2006.

Kiswanto, H., "Optimasi Sifat-Sifat Mekanik Genteng Press dengan Bahan Aditif Silika dan Dolomite", Skripsi, Jurusan Fisika Fakultas MIPA, Univeritas Negeri Semarang, 2011.

Nasir, M., Ratnasari, P., Islam, D.N.F., dan Shofiyani ,A., "Pengaruh Waktu High Energy Milling Terhadap Karakteristik Nanokaolin Capkala Asal Kalimatan Barat”, Jurnal Eksakta, Universitas Tanjungpura, Pontianak, 18, hal 201-209, (2017).

Rifai, M. dan Hartono, S. B., "Pengaruh Proses Sintering Pada Temperatur $800^{\circ} \mathrm{C}$ Terhadap Kekerasan dan Kekuatan Bending Pada Produk Gerabah", Jurnal Traksi, Universitas Muhammadiyah Semarang, 16, (2016).

Sanjaya, P. A., "Pengaruh Jumlah Penggilingan Tanah Liat Sebagai Bahan Pembuatan Genteng Terhadap Karakteristik Genteng Keramik Darmasaba", Jurnal Ilmiah Teknik Sipil, Fakultas Teknik Universitas Udayana, 13, hal 82-92, (2009).

SII 0021-1978, Mutu dan Uji Bata Merah Pejal, Yayasan Lembaga Pendidikan Masalah Bangunan, Bandung.

SNI 03-0106-1897, Mutu dan Uji Ubin Lantai Keramik.

Suwardono, Mengenal Pembuatan Bata Genteng, Genteng Berglasir, (Cetakan Pertama, CV.Yrana Widya, Bandung, 2002).

Widjanarko, S. B. dan Suwasito, T.S., "Pengaruh Lama Penggilingan Denga Metode Ball Mill Terhadap Rendemen dan Kemampuan Hidrasi Tepung Porang", Jurnal Pangan dan Agroindustri, Jurusan Teknologi Hasil Pertanian FTP Universitas Brawijaya Malang, 2, hal 79-85. (2014). 